\title{
Communication Skills of Biologically At-Risk Neonates
}

\author{
Alta Kritzinger, Brenda Louw and René Hugo \\ Department of Communication Pathology \\ University of Pretoria
}

\begin{abstract}
Early communication intervention has advanced to include neonatal assessment and management. Currently, however, there are limited diagnostic tools developed from a speech-language pathology and audiology perspective. The purpose of the study was to design a comprehensive neonatal communication assessment protocol and use it to describe the communication skills of 50 biologically at-risk neonates $(852 \mathrm{~g}-3060 \mathrm{~g}$ birthweight). The results indicated that the subjects' general development was within normal limits, but their communication abilities displayed a serious delay. A high risk register consisting of 13 factors predicting the subjects' communication abilities was compiled. The length of time before the subjects could successfully take bottle feeds was found to be the strongest predictor of their communication development. The study is of particular relevance to the present South African context which has an increased incidence of low birth weight, thus rendering an enlarged population of biologically at-risk neonates.
\end{abstract}

\section{OPSOMMING}

Vroeë kommunikasie-intervensie het ontwikkel om neonatale evaluering en intervensie in te sluit. Daar is egter beperkte evalueringshulpbronne beskikbaar wat ontwikkel is vanuit 'n spraak-taalpatologie- en oudiologie-perspektief. Die doel van die studie was om 'n omvattende neonatale kommunikasie-evalueringsprotokol te ontwerp en toe te pas om die kommunikasievaardighede van 50 biologiese-risikoneonate (852g-3060g geboortegewig) te beskryf. Die resultate het aangedui dat die proefpersone se algemene ontwikkeling binne normale perke was, maar dat hulle kommunikasievermoëns ' $n$ ernstige agterstand vertoon het. 'n Hoërisikoregister bestaande uit 13 risikofaktore wat die proefpersone se kommunikasievermoëns voorspel het, is opgestel. Die duur van die tydperk voordat die proefpersone suksesvol met 'n bottel kon voed, is as die beste voorspeller vir hulle kommunikasieontwikkeling bevind. Die studie is van besondere relevansie vir die huidige Suid-Afrikaanse konteks wat' $n$ verhoogde insidensie van lae gẹboortegewig vertoon en daarom 'n vergrote populasie van biologiese-risikoneonate oplewer.

KEY WORDS: neonatal communication assessment, biologically at-risk neonates, high risk register for communication development

\section{INTRODUCTION}

Early communication intervention for handicapped and at-risk infants and toddlers and their families is a new speciality of speech-language pathólogy and audiology, but is already accepted as the preferred form of intervention for this population (Rossetti, 1990). As the emphasis of health care shifted towards prevention and primary health care, and the need to treat infants from birth onwards became apparent, early communication intervention has advanced to include neonatal assessment and intervention. As a result of this development speech-language therapists and audiologists have become members of the multi-disciplinary team providing services in the neonatal intensive care unit (NICU). But there are still shortcomings regarding knowledge and assessment instruments. For example, in a survey of early communication intervention services in NICU's in the USA, Dunn, van Kleeck and Rossetti (1993) found that $91 \%$ of the speech-language pathologists involved in such services made use of informal assessment procedures. This indicates that early com- munication interventionists use a variety of resources available for neonatal assessments that may not be specifically designed for a comprehensive evaluation of these infants' communication skills and may not sufficiently address the specific needs of neonatal communication intervention.

In South Africa, however, neonatal intervention services are far less developed than in the USA. The provision of these services in the NICU is primarily devoted to hearing screening programmes (Malan, 1993). The lack of comprehensive speech-language pathology services in NICU's in South Africa is of particular concern as an increased incidence of infants born at biological risk occurs. According to Wainer (in Smith, 1992) the incidence of lowbirthweight infants is as high as $16 \%$ in Baragwanath Hospital, in Soweto, which serves a large underprivileged community. The accepted incidence of premature and lowbirthweight infants in technologically developed countries is much lower, and estimated between $6 \%$ and $8 \%$ (Gordon, 1987). The NICU population in South Africa also differs from that in developed countries as the majority of these 
infants are environmentally, as well as biologically at risk due to unfavourable socio-economic circumstances. Research on the communication skills of the NICU population in South Africa is necessary to provide guidelines for the improvement of NICU services provided by speechlanguage therapists and audiologists.

Although research from different disciplines has contributed to a body of knowledge about the communication skills of biologically at-risk neonates, it is fragmented and lacks a speech-language pathology perspective. The assessment of neonatal behaviour and developmental status has long been dominated by medical and developmental psy. chology studies that focus on the fullterm neonate (Brazelton, 1973; Rosenblith, 1992) and the biologically at-risk neonate. The research on biologically at-risk neonates provide knowledge about their behaviour (Brazelton, 1984) and neurological functioning (Majnemer, Brownstein, Kadanoff \& Shevell, 1992). The knowledge base about the communication skills of these neonates has also been expanded by studies on early interaction patterns between parents and their at-risk neonates (Klein \& Briggs, 1987), feeding patterns (Bu'Lock, Woolridge \& Baum, 1990) and hearing abilities (Brown \& Taxman, 1993; Pearce, Saunders, Creighton \& Sauve, 1988).

The importance of understanding the neonatal communication abilities of biologically at-risk infants is that it provides the speech-language therapist and audiologist with a prospective view of the first stages of their communication disorders and the conditions that interfere with the earliest parent-child communication interactions. Neonatal assessments, however, do not yet provide us with sufficient information to predict the course of further development (Brazelton, 1990; Rossetti, 1990). The neonate's behaviour is a powerful language, providing us with insight into prenatal and perinatal events. It is also an intricate language of interactions between various systems within the neonate as well as externally. According to Brazelton (1990) a simple linear model of assessment and prediction is not viable and ignores the synergy of developmental systems.

The aim of assessing neonatal communication skills of biologically at-risk neonates is to provide baseline data for early communication intervention and serial assessments. Such an assessment should consider at least four factors, namely:

- The NICU environment which provides ongoing nonsocial auditory, visual, kinaesthetic and tactile stimulation (noise, uninterrupted light, physical handling for routine care, and pain caused by necessary medical procedures) and limited and inconsistent social stimulation directed at the neonate when he/she displays readiness;

- The levels of consciousness that the neonate is able to maintain and control in response to his/her physical condition and inappropriate NICU environment stimulation;

- The different biological risk conditions that a specific neonate has been exposed to;

- The neonate's genetic endowment and prenatal events which may account for established risk factors, such as Down Syndrome (who are at-risk for low birthweight). (Als, 1986; Brazelton, 1987; Dunn et al., 1993)

Based on these factors the aim of the current study was to develop a comprehensive communication assessment protocol to describe the communication skills of biologically at-risk neonates.

\section{METHOD}

\section{AIMS}

- To design a communication assessment protocol for biologically at-risk neonates.

- To apply the neonatal communication assessment protocol to a group of biologically at-risk neonates.

- To determine correlations between the communication skills and other developmental areas of the group of biologically at-risk neonates.

- To identify risk factors relating to the communication skills of the group of biologically at-risk neonates in order to compile a high risk register of their communication development.

\section{SUBJECTS}

A descriptive survey was conducted. Fifty subjects were randomly selected from the population of biologically atrisk neonates and were required to present with prematurity ( 37 weeks or less gestation) and/or low-birthweight (2 500g or lower birthweight). The subjects had to be discharged from the incubator less than two days, but had to be still in the NICU, and in a medically stable condition as judged by their doctors. Subject selection was limited to four hospitals in the urban area of Pretoria.

\section{Biological and established risk factors}

The subjects were assessed at an average corrected age of 38 weeks, ranging from 34 to 43 weeks. Their average chronological age at assessment was, however, 26 days, ranging from 1 to 75 days (see Table 1 no 1 ).

Table 1 provides information regarding the general characteristics (no 1 to 4), biological risk conditions (no 5 to 19) and established risk conditions for development (no 20 ) of the subjects. According to Table 1 the sample displayed large differences in birthweight (from extremely low birthweight to normal birthweight) and gestational age (from extremely premature to fullterm). It may appear as if some of the subjects did not meet the selection criteria, but one subject displayed mild prematurity and normal birthweight $(3060 \mathrm{~g})$, while four subjects were fullterm, but small-for-gestational age.

$30 \%$ of subjects who were small-for-gestational age (see Table 1 no 16), may be associated with biological risk factors coupled with environmental risk factors. The sample did not, however, reflect a high percentage of environmentally at-risk infants as can be expected elsewhere in South Africa as the subjects were mostly from middle-income families living in an urban area.

\section{Non-8ocial environmental risk factors}

Apart from the biological and established risk factors provided in Table 1 the NICU environment was investigated for possible non-social environmental risk factors. The noise levels in one of the NICU's that were utilised for subject recruitment were measured with a Rion NA24 soundlevel meter. These measurements are provided in Table 2 in order to give an account of the noise levels that the subjects were exposed to during their stay on the warm table and in the incubator. As consistent high in- 
tensity noise levels hold the greatest potential for hearing damage, the noise caused by oxygen supplied through corrugated tubing can be singled out as a high risk condition for cochlear damage in the subjects of this study. Boettcher, Henderson, Gratton, Danielson and Byrne (1987) found a potential interaction between high intensity noise levels in the NICU and the use of Aminoglycoside therapy. It is suggested that the developing cochlea of premature neonates is more vulnerable for the joint effects of high intensity noise and the use of ototoxic drugs.

The noise levels of the NICU reflected in Table 2 may also have a non-auditory effect on the subjects, as they contribute to sensory overstimulation and interfere with communication interaction by masking the human voice. It also appeared that the seriously ill subjects were exposed to more treatment procedures involving the highest

Table 1: Description of subjects

\begin{tabular}{|c|c|}
\hline Feature or risk factor & Qualitative Description \\
\hline 1. Chronological age at assessment & $\begin{array}{l}\text { Mean: } 26 \text { days } \\
\text { Range: } 1-75 \text { days }\end{array}$ \\
\hline 2. Gender & 28 girls; 22 boys \\
\hline 3. Number of subjects visited daily by parents & 42 subjects $(84 \%)$ \\
\hline 4. Number of subjects receiving breast milk & 26 subjects $(52 \%)$ \\
\hline 5. Gestational age & $\begin{array}{l}\text { Mean: } 34 \text { weeks } \\
\text { Range: } 26-40 \text { weeks }\end{array}$ \\
\hline 6. Birthweight & $\begin{array}{l}\text { Mean: } 1906 \mathrm{~g} \\
\text { Range: } 852-3060 \mathrm{~g}\end{array}$ \\
\hline 7. Number of days in incubator & $\begin{array}{l}\text { Mean: } 24 \text { days } \\
\text { Range: } 1-75 \text { days }\end{array}$ \\
\hline 8. Number of days before bottle-fed & $\begin{array}{l}\text { Mean: } 17 \text { days } \\
\text { Range: } 0-74 \text { days }\end{array}$ \\
\hline 9. Multiple pregnancy & $\begin{array}{l}14 \text { subjects }(28 \%) \\
7 \text { pairs of twins }\end{array}$ \\
\hline 10. Respiratory distress syndrome & 22 subjects $(44 \%)$ \\
\hline 11. Perinatal infection : & 38 subjects $(76 \%)$ \\
\hline 12. Intra-cranial haemorrhage & 5 subjects $(10 \%)$ \\
\hline 13. Aminoglycoside therapy & 27 subjects $(54 \%)$ \\
\hline 14. Duration of Aminoglycoside therapy & $\begin{array}{l}\text { Mean: } 11 \text { days } \\
\text { Range: } 7-63 \text { days }\end{array}$ \\
\hline 15. 5 minute Apgar score & $\begin{array}{l}\text { Mean: } 8 \\
\text { Range: } 2-10\end{array}$ \\
\hline 16. Small-for-gestational-age & $15(30 \%)$ \\
\hline 17. Jaundice & 42 subjects $(84 \%)$ \\
\hline 18. Phototherapy for jaundice & 38 subjects $(76 \%)$ \\
\hline 19. Recurrent apnoea attacks & 12 subjects $(24 \%)$ \\
\hline 20. Family history of hearing loss & 2 subjects $(4 \%)$ \\
\hline 21. Other non-infective conditions* & 6 subjects $(12 \%)$ \\
\hline
\end{tabular}

*Key:Other non-infective conditions included hydrocephalus, craniostenosis, blindness and congenital abnormality of limb. 
intensity noise levels. The noise caused by life-supporting systems can therefore be considered as a risk factor for the subjects' hearing abilities and the development of communication interaction skills.

\section{COMMUNICATION ASSESSMENT PROTOCOL}

Various sources from the literature were used to design a neonatal communication assessment protocol which would serve to collect a case history (Rossetti, 1990), assess hearing abilities (Proctor \& Kennedy, 1990), precursors of cognitive abilities (Brazelton 1987), motor development (Clarke-Stewart \& Friedman, 1987), oral-motor functioning (Morris \& Klein, 1987) and communication skills. These include precursors of language use (Klein \& Briggs, 1987; Sparks, 1989), precursors of language form (Louw, 1986; Proctor, 1989) and precursors of language content (Lahey, 1988) (see Kritzinger, 1994 Appendix B,C \& D). The zoom lens model as suggested by van Kleeck and Richardson (1988) was used as a theoretical framework for designing the protocol and conducting the research project. Figure I provides a summary of the neonatal communication assessment model.

\section{PROCEDURE}

\section{DATA COLLECTION}

As a first step to determine the exact sequencing of all the components of the assessment protocol and to gain clinical skills in the unknown field of neonatal communication assessment, a pilot study was carried out on ten fullterm neonates. As a result of the practical experience and insight gained from the pilot study, specific procedures were established for the collecting of data on the 50 subjects of the main study, namely:

- Data collection was done in the afternoons to ensure less disruption of the busy routines of the NICU during mornings.
- The subjects were assessed half an hour before feeding to avoid deep sleeping and difficulties of waking the subjects.

- Data collection began by measuring the middle-ear functioning while the subject was still sleeping and less likely to move.

- This was followed by behaviour observation audiom. etry while the subject was sleeping or in a quiet state.

- After audiometric measurements were completed the subject was usually awake and interactive behaviour could be elicited for the evaluation of communication and cognitive skills.

- Motor and oral-motor skills were evaluated before feeding, as oral reflexes are depressed after feeding. Observation of feeding skills concluded the assessment protocol.

- Relevant data from the case history was collected last in order to avoid biased observations (Kritzinger, 1994).

- All measurements, responses and observations were immediately recorded on the scoresheets of the Case His. tory: Biological and Established Risk Factors and Communication Assessment Scales for Infants at Biological Risk: Neonatal Period (Kritzinger, 1994 Appendix B, \& D).

- After experience in assessment were gained from the ten subjects of the pilot study, data collection was done by only one examiner. As recommended by Brazelton (1973) no more than two subjects were assessed on one day, as fatigue may interfere with the examiner's accuracy.

\section{ANALYSIS OF DATA}

Data was analyzed and statistically processed in order to present qualitative and quantitative results of the survey. By following the different assessment levels of the zoom lens model (van Kleeck \& Richardson, 1988), the results were compared to normal development and interpreted by indicating intrasystem interactions and finally presenting a broad perspective by indicating intersystem interactions of the communication skills of the subjects.

Table 2: Noise levels in a NICU

\begin{tabular}{|l|c|c|}
\hline General sources of noise & Persistent & Intermittent \\
\hline Noise level at subject in head box & yes & nes \\
\hline Noise level at subject on warm table & & no \\
\hline Additional sources of noise & yes & no \\
\hline Heart monitor: high frequency impulse noise & yes & no \\
\hline Heart monitor: low frequency impulse noise & no \\
\hline Heart monitor alarm & no & yes \\
\hline Ventilator monitor & no & yes \\
\hline Warm table monitor & no & yes \\
\hline Voices and trolley & yes & no \\
\hline Oxygen fed through corrugated tubing & & \\
\hline
\end{tabular}




\begin{tabular}{|c|c|}
\hline VARIABLES & ASSESSMENT AREAS \\
\hline Biological variables & Case history \\
\hline Environmental variables & Noise levels in NICU \\
\hline $\begin{array}{l}\text { Behavioural variables: } \\
\text { - Hearing system } \\
\text { - Motor system } \\
\text { - Cognitive system }\end{array}$ & $\begin{array}{l}\text { - Hearing and middle-ear functioning* } \\
\text { - Gross motor and oral motor skills } \\
\text { - Precursors of cognition }\end{array}$ \\
\hline
\end{tabular}

\begin{tabular}{|cc|}
\hline Step 2 & INTRASYSTEM ANALYSIS \\
\hline \multicolumn{1}{|c|}{ VARIABLES } & \multicolumn{1}{c|}{ ASSESSMENT AREAS } \\
\hline - Communication system & - Precursors of language use \\
& - Precursors of language form \\
& - Precursors of language content \\
\hline
\end{tabular}

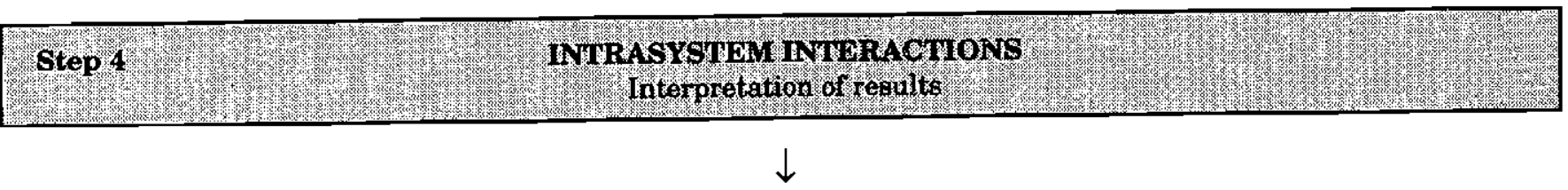

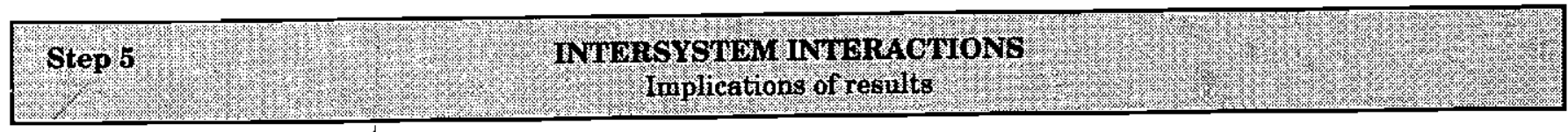

*Key:Equipment used for the hearing assessment included the Weiss Neometer providing calibrated high and low frequency narrowband noise for behaviour observation audiometry and the GSI 28A Auto Tymp (Grason-Stadler, Inc) for the evaluation of middle-ear functioning.

Figure I: Neonatal communication assessment model for biologically at-risk infants

\section{RESULTS AND DISCUSSION}

Figure II presents an overall view of the average functioning of the 50 subjects for the eight areas of assessment.

According to Figure II the subjects presented with normal levels of functioning (values of 7 to 10 according to the rating scale as suggested by Allen \& Alexander, 1992) for hearing abilities, middle-ear functioning, motor and oral-motor skills, whereas precursors for cognition and language use, form and content displayed a delay in development. Precursors for language use can be singled out as the developmental area displaying the greatest delay. The subjects' normal developmental levels are comparable to results of research done by Aylward, Gustafson, Verhulst \& Colliver (1987) and Gorga, Stern, Nass \& Nagler (1988) for subjects ranging from minimal to extreme prematurity. These studies found that most sub- jects displayed no neurological or motor disorders in the neonatal period. Studies on extremely premature neonates (Majnemer et al., 1992; Piper, Kunos, Willis \& Mazer, 1985; Touwen, 1990) however, found large differences in general development in comparison with fullterm neonates. It therefore appears that the more premature the neonates are, the greater the delay in their general development.

The delays in cognitive and communication development displayed by the subjects indicate limited interaction with their environment and caregivers. These findings are recognized by various researchers as typical neonatal behaviour of biologically at-risk infants (Als, 1986; Brazelton, 1984; Stjernqvist \& Svenningsen, 1990). It is suggested that these disordered interaction patterns are related to sensory overstimulation, absence of contingent interaction with caregivers and a lack of rhythmicity and routines in the $\mathrm{NICU}$ (Als, 1986). 
Figure III presents the results of the Spearman correlation coefficients conducted to determine significant correlations $(<0,5)$ between the subjects' developmental levels across the different developmental areas. All significant correlations that occurred were positive, indicating the subjects' improvement or delay in one developmental area displayed an improvement or delay in the correlated developmental area as well. According to Figure III significant positive correlations occurred between the assessment areas of the communication protocol representing different aspects of behaviour (motor and oral-motor skills and precursors of cognition, language use, form and content). Those assessment areas measuring physiological

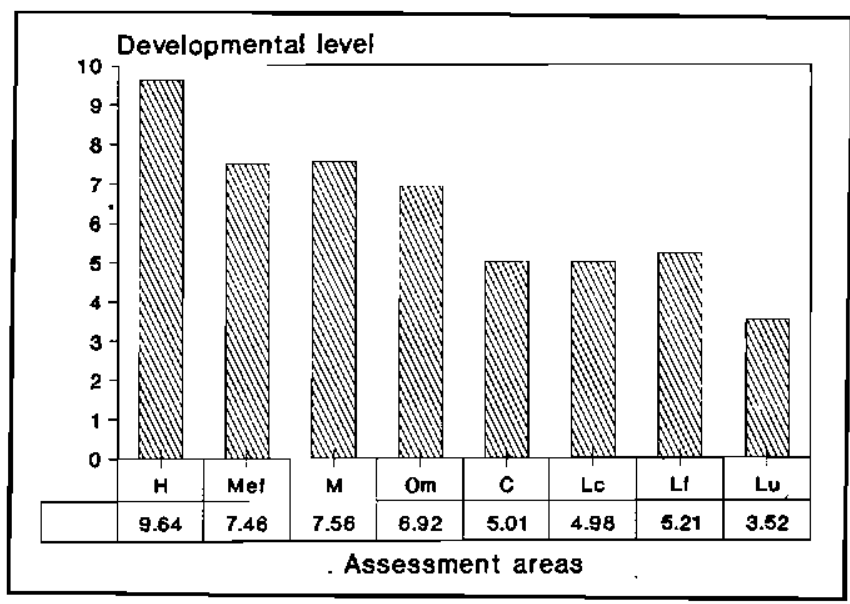

Figure II: Average developmental levels of subjects, $\mathbf{N}=\mathbf{5 0}$

Key: $\mathrm{H}=$ Hearing abilities; $\mathrm{Mef}=$ Middle ear functioning; $\mathrm{M}=$ Motor skills; Om= Oral-motor skills; $\mathrm{C}=$ Precursors of cognition; $L c=$ Precursors of language content; $\mathrm{Lf}=$ Precursors of language form; Lu= Precursors of language use

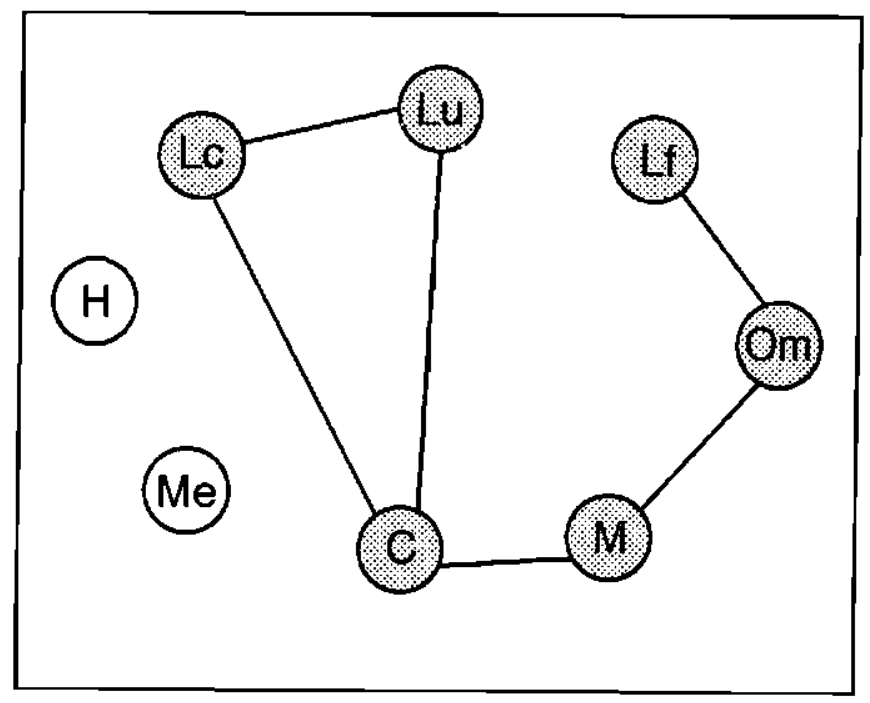

Figure III: Significant correlations between the results of the different developmental areas, $N=50$

Key: $\mathrm{H}=$ Hearing abilities; $\mathrm{Me}=$ Middle ear functioning; $\mathrm{M}=$ Motor skills; $\mathrm{Om}=$ Oral-motor skills; $\mathrm{C}=$ Precursors of cognition; Lc= Precursors of language content; Lf= Precursors of language form; Lu= Precursors of language use functioning (the subjects' hearing abilities and middle-ear functioning) did not indicate any intersystem interactions as they require different parameters of assessment compared to behaviour.

A detailed analysis of the results based on Figure II and Figure III is supplied by discussing each developmental area separately.

\section{GENERAL DEVELOPMENTAL SYSTEMS: INTERSYSTEM ANALYSIS AND INTERACTIONS}

\section{Hearing abilities}

The subjects' response levels were indicative of normal hearing abilities in a non-soundproof room. No sensoryneural hearing loss was detected among the subjects and risk factors such as the noise levels in the NICU, the use of ototoxic drugs (see table 2) and all other risk conditions described in the High Risk Criteria for the Identification of Hearing Loss in Children (ASHA, 1989) did not seem to have affected their hearing abilities.

It was found that doctors in the hospitals studied, carefully monitored the ototoxic levels in the blood when such drugs were used and often avoided using these drugs. It could therefore be that reported incidence of sensory-neural hearing loss between $2 \%$ and $10 \%$ among the NICU graduates (Salamy \& Eldridge, 1991), served to focus the attention on preventative measures of which we see the results now already.

\section{Middle-ear functioning}

Three different aspects of the results on the middle-ear functioning of the subjects are discussed, namely abnormal middle-ear measurements, acoustic reflexes and tympanograms.

The measurement of 7,48 (see Figure II) indicates normal middle-ear functioning for the group as a whole. $20 \%$ of the subjects, however, displayed abnormal middle-ear measurements for static compliance, middle-ear pressure and the shape of the tympanogram. These findings seem to indicate an increased incidence of abnormal middle-ear functioning among the subjects when compared with studies on middle-ear functioning of fullterm neonates, which found the incidence of middle-ear pathology between $0 \%$ (Zarnoch \& Balkany, 1977) and 4,1\% (Mann, 1986) in that population. It has been suggested that abnormal middleear functioning is related to the prolonged use of nasogastric tube feeding resulting in decreased ventilation of the middle-ear as no swallowing is required for this kind of feeding.

There is, however, no clarity about the nature of the abnormal middle-ear measurements displayed by the subjects as these neonates have just completed courses of antibiotics that would have cleared up otitis media with effusion as well. Clinical experience indicates the difficulty of diagnosing abnormal middle-ear functioning as the premature external meatus is very narrow and limits the visual inspection of the tympanic membrane. It is therefore suggested that increased fluid in the middle-ear as measured in $20 \%$ of the subjects may be sterile, but can still cause a conductive hearing loss. Although this hearing loss will only influence communication development when it recurs frequently, early detection of abnormal middle-ear functioning in biologically at-risk neonates may lead to the early identification of those who are otitis media-prone. Further research is necessary to establish if this 
is indeed the way to identify otitis media-prone infants at biological risk. Early identification of otitis media in biologically at-risk neonates can ensure early treatment resulting in decreasing the negative effects on their communication development as various studies have already found a high incidence of otitis media among biologically at-risk infants (Pearce et al., 1988).

The subjects' acoustical reflexes displayed normal values, but could only be elicited after an average of four attempts. These findings are in agreement with other studies finding neonatal acoustical reflexes difficult to elicit (Mann, 1986; Walters \& Shimizu, 1990).

Finally, $94 \%$ of the subjects displayed type D and Type E tympanograms indicating highly mobile middle-ear sys. tems. Research done by Keith (1975) and Mann (1986) on fullterm neonates and Zarnoch and Balkany (1977) on biologically at-risk neonates indicates a high incidence of mobile middle-ear systems that can be related to the incomplete ossification of the middle-ear system in fullterm neonates as well as in premature neonates. The incidence of mobile middle-ear systems in these three studies, how. ever, are not as high as in the present study. The findings of the present study on the mobility of the subjects' middle-ear systems are therefore only partly in agreement with previous studies.

\section{Motor skills}

The subjects' average motor skills were within normal limits and are comparable to the studies of Aylward et al. (1987) and Gorga et al. (1988). Uncontrolled body movements and lack of an overall extension pattern can be singled out as the subjects' typical motor behaviour. According to Morris and Klein (1987) the lack of a physiological flexion pattern of the body is characteristic of premature neonates as they are born too soon to be forced into flexion due to decreased intra-uterine space.

\section{Oral-motor skills}

The subjects' oral-motor skills displayed values just below the average $(6,92)$. The' subjects were assessed at a stage when they had already overcome most of their feeding problems and shortly before discharge from the NICU. Table 1 no 8 indicates that the subjects did experience feeding problems prior to assessment, some to the extent that it took them 75 days to bottle-feed satisfactorily. A qualitative analysis of the results revealed depressed rooting reflexes, prolonged dependence on nasogastric tube-feeding (44\% of subjects) and prolonged duration of feeding (only $28 \%$ of the subjects could complete their feeding within 20 minutes) as the remainder of their feeding difficulties. The feeding difficulties experienced by the subjects are similar to those described by Bu'Lock et al. (1990), Jaffe (1989) and Morris and Klein (1987). It is suggested the feeding difficulties of biologically at-risk neonates are related to neurological disorganization and the predominant extension pattern of the body. These results, supported by the Spearman correlation coefficients (see Figure III) indicated that relationships exist between the subjects' motor and oral-motor skills, therefore demonstrating interactions within the motor system.

\section{Precursors of cognitive skills}

The results indicate that the subjects evidenced a delay in the development of precursors of cognitive development. On average the subjects displayed difficulties with actively attending to environmental stimuli. According to Brazelton (1984) the neonates' characteristic ability to control stimuli by changing their levels of consciousness (from sleep to alertness) may be the most predictive aspect of their behaviour. The subjects' passive state can therefore be ascribed to their limited ability for organization and intergration of stimuli within and from the environment. These findings are also supported by Majnemer et al. (1992) and Stjernqvist and Svenningsen (1990).

\section{COMMUNICATION SYSTEM: INTRASYSTEM ANALYSIS AND INTERACTIONS}

\section{Precursors of language use}

The results of the development of the precursors of language use revealed the subjects' lowest level of development of all areas assessed. Characteristic neonatal communication interaction behaviour such as eye contact, imitation of facial expressions and synchronized interactions occurred rarely. These results display clear intersystem interactions between the cognitive and communicative systems (see Figure III as well) of the subjects and can be explained in the same way as the subjects' passive responses to non-social stimuli (development of precursors of cognition). The development of the precursors of language use indicates that the subjects' social interaction with the environment was poor. This can be related to the inconsistent and limited social interaction provided by the NICU environment. Comparison of the subjects' severe delay in developing precursors for language use to the other results, appear to support the opinion of Rosenblith (1992) namely, that infants at biological risk exhibit a specific vulnerability for communication disorders. When taken into consideration that precursors of language use are the first forms of communication to develop (Lahey, 1988), the results of this study may point to some of the underpinnings of the communication disorders of biologically at-risk infants.

\section{Precursors of language form}

As indicated in Figure II the subjects displayed a delay in the development of precursors of language form. It seemed that their typical vocal behaviour was still undifferentiated and reflexive in nature, again indicating limited interaction with the environment. These results are supported by Morris and Klein (1987) by their description of the limited vocal behaviour of biologically at-risk neonates as they do not cry to signal for hunger.

The subjects' results regarding the development of precursors for language form displayed significant positive correlations with their oral-motor skills (see Figure III). These findings indicate that interactions between the motor and communication systems occurred, which is also recognized in the literature (Morris \& Klein, 1987).

\section{Precursors of language content}

Although the subjects displayed normal hearing abilities, their development of listening skills as precursors of language content demonstrated delay. Listening behaviour, distinguished by sustained attention, arrest of activity and alertness (Brazelton, 1973) was seldomly observed. The lack of these responses also demonstrates the subjects' limited interaction with the social and non-social environment, thus possibly explaining the existence of the correlations displayed between the development of pre- 
cursors of language use and cognition (see Figure III).

The results of the subjects' general and communication development indicated interactions across developmental systems as well as intrasystem interactions. This serves as a means to provide a wide angle perspective on the subjects' communication development. The results also indicate the synergy of the different developmental systems and demonstrates the difficulties that the subjects experienced to gain control over their developmental systems by means of regulation and organization of their behaviour.

In summary, the subjects gave the impression of a neonate with normal hearing abilities, but a high risk for otitis media. $\mathbf{S}($ he) mainly lies quietly in an extension pattern and has not fully mastered independent feeding skills. This neonate is mostly in a semi-alert state, pays attention to auditory and visual stimuli momentarily, cries or vocalizes seldom and attends only fleetingly to human contact and voices. This neonate is tiny, vulnerable, passive and has insufficient skills for communication interaction when compared to his / her fullterm counterpart who has been "prewired" (Owens, 1984, p21) for communication.

IDENTIFICATION OF RISK FACTORS RELATING TO THE SUBJECTS' COMMUNICATION DEVELOP. MENT
According to Rossetti (1993) the early identification of communication disorders of biologically at-risk neonates is one of the most important factors contributing to the success of early communication intervention. The use of a high risk register for communication disorders implies that biologically at-risk neonates who are at special risk for communication disorders, can be identified before being discharged from the NICU and early communication intervention can continue without any interruption between neonatal and postnatal intervention.

A stepwise regression analysis was done in order to identify significant independent variables (on a $5 \%$ level of significance) correlating with the subjects' delayed communication development. Thirteen significant independent variables were identified as significant risk factors that predicted the subjects' delayed communication development. This implies that the presence of a risk factor had a negative influence on the subjects' communication functioning. Table 3 provides these risk factors in order of predictability as well as the different aspects of communication development that they were related to.

According to Table 3 ten risk factors were directly related to the subjects' biological conditions. Birthweight and prematurity are among these risk factors, but they were not the strongest predictors of the subjects' commu-

Table 3: Significant risk factors of communication development in order of predictability, $N=50$

\begin{tabular}{|c|c|c|c|}
\hline Risk factor & Type of risk & Communication behaviour & \\
\hline 1. Success with bottle feeding & Biological risk & $\begin{array}{l}\text { - Precursors of language use } \\
\text { - Precursors of cognition } \\
\text { - Oral motor skills } \\
\text { - Motor skills }\end{array}$ & \\
\hline 2. Receive breast milk & Environmental risk & $\begin{array}{l}\text { - Precursors of language content } \\
\text { - Precursors of language form } \\
\text { - Motor skills }\end{array}$ & \\
\hline 3. Frequency of parental visits in NICU & Environmental risk & $\begin{array}{l}\text { - Oral motor skills } \\
\text { - Motor skills }\end{array}$ & \\
\hline 4. Gestation age (prematurity) & Biological risk & $\begin{array}{l}\text { - Precursors of language use } \\
\text { - Precursors of language form }\end{array}$ & $\begin{array}{l}\vdots \\
\vdots \\
\vdots\end{array}$ \\
\hline 5. Small-for-gestational-age & Biological risk & $\begin{array}{l}\text { - Precursors of language form } \\
\text { - Middle-ear functioning }\end{array}$ & 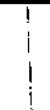 \\
\hline 6. Gender (masculine) & Biological risk & $\begin{array}{l}\text { - Middle-ear functioning } \\
\text { - Precursors of language form }\end{array}$ & $\begin{array}{l}1 \\
1 \\
1\end{array}$ \\
\hline 7. Birthweight & Biological risk & - Oral motor skills & \\
\hline 8. Multiple births (twins) & Biological risk & - Middle-ear functioning & \\
\hline 9. Perinatal infection & Biological risk & - Precursors of language content & \\
\hline 10. Intracranial haemorrhage & Biological risk & - Precursors of language form & \\
\hline 11. Apnoea attacks & Biological risk & - Precursors of cognition & \\
\hline 12. Respiratory distress syndrome & Biological risk & - Precursors of language cóntent & \\
\hline 13. Non-infective conditions & Established risk & - Middle-ear functioning & \\
\hline
\end{tabular}


nication functioning as regarded in the literature (Rossetti, 1993). The strongest predictor of the subjects' communication development was their success with bottle-feeding, as measured by the number of days taken to achieve successful bottle-feeding. The quicker the subjects could feed independently, the better their communication development was. The subjects' success with bottle-feeding predicted their functioning on a wide range of developmental areas, namely social and non-social interaction skills as well as motor and oral motor development, representing the communication, cognitive and motor systems. This indicates that feeding skills could be singled out as a basic prerequisite for the subjects' communication development. These findings are in agreement with Alexander (1990) who considers impaired vegetative functioning as one of the earliest signs of developmental disorders.

In considering all the different risk factors indicated in Table 3, lack of success with bottle-feeding was the only parameter that provided information about the subjects' developmental status. Some of the other biological risk factors (no 9 to 12) merely indicated the subjects' recovery from perinatal conditions, whereas birthweight, prematurity, gender and multiple births indicate well-known risks, but did not indicate how individual neonates react to these conditions.

Table 3 also indicates that environmental risk factors, as measured by parental involvement, negatively influenced the subjects' communication development. The parents' involvement was measured by providing breast milk for feeding and the frequency of their visits to the
NICU. Those subjects who received breast milk (mostly expressed breast milk received via tube feeding or bottlefeeding) benefitted from the interaction with mothers as these mothers had to bring the milk to the NICU daily and often fed the subjects themselves. The parents' regular involvement with the subjects in the NICU had a positive effect on aspects of their communication development as well as their motor and oral motor skills. The importance of parental involvement in the NICU is also stressed by various authors (Als, 1986; Jacobson \& Shubat, 1991; Sparks, 1989).

The last parameter indicated in Table 3 were conditions that represent established risks (also see Table 1 no 20) and indicates the close relationship existing between biological risks and established risks. Established risk conditions can have their origin in prenatal stress conditions and are usually associated with retarded intrauterine growth. This implies that the risk status of an infant at biological risk can already begin during prenatal development. The established risk conditions as identified in this study, however, had a limited influence on the subjects' communication development, namely on their middle-ear functioning.

The thirteen risk conditions as indicated in Table 3 can therefore be considered as high risk factors for the subjects' neonatal communication development and are presented in Table 4. The predictability of these risk factors for later communication development must still be established by further research in the form of longitudinal studies.

In conclusion, the results of the study highlighted cer-

Table 4: High risk register for the prediction of the subjects' communication development, $\mathrm{N}=50$

\begin{tabular}{|c|c|}
\hline Parameter & Risk factor \\
\hline 1. Feeding & $\begin{array}{l}\text { The greater the number of days before successful bottle feeding, the greater } \\
\text { the risk }\end{array}$ \\
\hline 2. Receiving breastmilk in NICU & $\begin{array}{l}\text { Mother not supplying breast milk implies less communication interaction } \\
\text { with one caregiver and a risk for communication delay }\end{array}$ \\
\hline 3. Parental visits in NICU & The lower the frequency of parental visits, the greater the risk \\
\hline 4. Gestation age & The lower the gestation age, the greater the risk \\
\hline 5. Small-for-gestational age & $\begin{array}{l}\text { The presence of intra-uterine growth retardation implies a risk for commu- } \\
\text { nication delay }\end{array}$ \\
\hline 6. Gender & Boys displayed as greater risk for communication delays \\
\hline 7. Birthweight & The lower the birthweight, the greater the risk \\
\hline 8. Multiple births & Twins displayed a greater risk for communication delay \\
\hline 9. Perinatal infection & The presence of an infection implies a risk for communication delay \\
\hline 10. Intracranial haemorrhage & The presence implies a risk for communication delay \\
\hline 11. Apnoea attacks & The presence implies a risk for communication delay \\
\hline 12. Respiratory distress syndrome & The presence implies a risk for communication delay \\
\hline 13. Non-infectious conditions & $\begin{array}{l}\text { The presence of established risk factors implies a risk for communication } \\
\text { delay }\end{array}$ \\
\hline
\end{tabular}


tain aspects of neonatal communication abilities of biologically at-risk infants such as:

- The incidence of sensory neural hearing loss. The results of the study add to the unsolved question in the literature about the incidence of sensory-neural hearing loss among the NICU population;

- Neonatal middle-ear functioning of infants at biological risk and the fact that the literature provides very limited guidelines for neonatal tympanometry. Further research into the early identification of otitis prone infants at biological risk is necessary;

- The serious delay in communication interaction skills compared to other aspects of language development and general development.

- The effects of biological as well as environmental risk factors on neonatal communication abilities as evidenced in the proposed high risk register.

It therefore appears that the results of the study, as obtained from the proposed assessment protocol, provided comprehensive information about the communication abilities of a group of biologically at-risk neonates, both from a speech-language pathology perspective as well as from an audiological viewpoint.

\section{CONCLUSIONS}

Neonatal communication intervention is the first link in the chain of continuous service delivery from birth to schoolgoing age to biologically at-risk infants and their families. This study focused attention on the earliest communication abilities of biologically at-risk infants. Such an approach contributes to a perspective that retrospective studies, which have dominated this field of study in the past, cannot provide.

The neonatal perspective underscores the detrimental influence of the NICU environment on the communication development of biologically at-risk neonates. The results of the study suggest that the noise levels in the NICU may pose a risk for hearing loss as well as interference with communication interaction. The results of the study also indicate that appropriate parental involvement in the NICU can make a difference to these neonates' early communication skills.

A neonatal perspective further provides first-hand knowledge of the different biological and established risk conditions as well as neonatal communication behaviour and the interactions of these two aspects with one another. These aspects need to be explained to parents to ensure bonding and effective parent-infant communication interaction when the neonate displays readiness.

It is therefore clear that a neonatal perspective on the communication abilities of biologically at-risk infants can contribute to the effectiveness of early intervention and adds a new dimension to the role of the early communication interventionist. The involvement of the speech-language therapist and audiologist in the multidisciplinary neonatal intervention team implies an extension of the field of communication pathology demanding specialized knowledge and clinical skills. This has implications for undergraduate training as well for continuing education of qualified professionals.

Another implication of the speech-language therapist's and audiologist's involvement in neonatal intervention is the opportunity to provide services on the level of secondary prevention of communication disorders and in this way responding to the objectives of early communication intervention, i.e., preventing minor problems from becoming serious and new problems from developing (ASHA, 1991). The current study provides a tool for screening by means of the proposed high risk register (see Table 4) as well as a neonatal communication assessment protocol for comprehensive evaluation purposes.

The proposed high risk register for identification of those biologically at-risk neonates who are also at risk for communication disorders is a first attempt at such a strategy of early detection of communication pathology. The validity and reliability of the high risk register must, however, still be established as in the case of the well-known High Rish Criteria for the Identification of Hearing Loss in Children (ASHA, 1989). Although a high risk register will always have limitations as there are still many unmeasurable causes of communication pathology, it can be of much clinical value. The specific items of the proposed high risk register, especially the neonate's success with bottle feeding (see Table 4), requires information that is readily available from the neonate's case history file or from the parents. The high risk register can therefore be a cost effective screening instrument to be used in primary health care in South Africa. In a transdisciplinary context, community nurses may be trained to identify those neonates exhibiting risk factors for follow-up by early communication intervention specialists.

This study provides a clinical assessment tool for the evaluation of neonatal communication abilities of biologically at-risk infants. The neonatal communication assessment protocol is as far as is known, unique in South Africa. It is also a first attempt to objectify neonatal intervention by means of assessment. Neonatal intervention in the South African context, however, still poses many challenges. This research project focused only on biologically at-risk neonates and did not study those who are also environmentally at-risk. Further research needs to be conducted regarding the concerns of the most needy of the South African biologically at-risk population. Additional research will enhance the development of early communication intervention in South Africa, thereby giving priority to a strategy for the secondary prevention of communication disorders. Early communication intervention is a key strategy that needs to be employed to cope with the large numbers of clients and the limited number of speech-language therapists and audiologists.

\section{CORRESPONDENCE SHOULD BE ADDRESSED TO:}

Alta Kritzinger, Department of Communication Pathology, University of Pretoria, Pretoria 0002

\section{REFERENCES}

Alexander, R. (1990). Oral-motor and respiratory-phonatory assessment. In Gibbs, E.D. \& Teti D.M. (eds.) Interdisciplinary Assessment of Infants. Baltimore: Paul H. Brooks Publishing Company.

Allen, M.C. \& Alexander, G.R. (1992). Using gross motor milestones to ịdentify very preterm infants at risk for cerebral palsy. Developmental Medicine and Child Neurology, 34:226232.

Als, H. (1986). A synactive model of neonatal behavioral organization: Framework for the assessment of neurobehavioral development in the premature infant and for 
support of infants and parents in the neonatal intensive care environment. In Sweeny J.K. (ed.) The High-Risk Neonate: environment. In Sweeny J.K. (ed.) The High-Risk Neonate: Press.

ASHA (1989). Audiologic screening of infants who are at risk for hearing impairment. ASHA, March:89-92.

ASHA (1991). The prevention of communication disorders tutorial. ASHA Supplement, 33(9):15-39.

Aylward, G.P., Gustafson, N., Verhulst, S.J. \& Colliver, J.A. (1987). Consistency in the diagnosis of cognitive, motor and neurologic function over the first three years. Journal of Pediatric Psychology, 12(1):77-98.

Boettcher, F.A., Henderson, D., Gratton, M.A., Danielson, R.W. \& Byrne, C.D. (1987). Synergistic interactions of noise and other ototraumatic agents. Ear and Hearing, 8(4):192-211.

Brazelton, T.B. (1973). Neonatal Behavioral Assessment Scale. London: William Heinemann Medical Books Ltd.

Brazelton, T.B. (1984). Neonatal Behavioral Assessment Scale. London: Blackwell Scientific Publications Ltd.

Brazelton, T.B. (1987). Behavioral competence of the newborn infant. In Avery, G.B. (ed.) Neonatology: Pathophysiology and the Management of the Newborn. Philadelphia: J.B. Lippincott.

Brazelton, T.B. (1990). Saving the bathwater. Child Development, 60:1661-1671.

Brown, D.P. \& Taxman, S.I. (1993). Five years of Neonatal Hearing Screening: A Summary. Infant-Toddler Intervention: The Transdisciplinary Journal, 3(2):135-150.

Bu'Lock, F. Woolridge, M.W. \& Baum, J.D. (1990). Development of co-ordination of sucking, swallowing and breathing: Ultrasound study of term and preterm infants. Developmental Medicine and Child Neurology, 32:669-678.

Clarke-Stèwart, A. \& Friedman, S. (1987). Child Development: Infancy through Adolescence. New York: John Wiley \& Sons.

Dunn, S.L., Van Kleeck, A. \& Rossetti, L.M. (1993). Current roles and continuing needs of speech-language pathologists working in neonatal intensive care units. American Journal of SpeechLanguage Pathology, May:53-64.

Gordon, H.H. (1987). Perspectives on neonatology. In Avery, G B. (ed.) Neonatology: Pathophysiology and Management of the Newborn. Philadelphia: J.B. Lippincott.

Gorga, D., Stern, F.M., Ross, G. \& Nagler, W. (1988). Neuromotor development of preterm and full-term infants. Early Human Development, 18:137-149.

Jacobson, C.H. \& Shubat, S.J. (1991). Hospital-based communication intervention with the at-risk newborn. Infant-Toddler Intervention: The Transdisciplinary Journal, 1(1):27-35.

Jaffe, M.B. (1989). Feeding at-risk infants and toddlers. Topics in Language Disorders, 10(1):13-25

Keith, R.W. (1975). Middle ear function in neonates. Acta Otolaryngologica, 101:376-379.

Kleiń, M.D. \& Briggs, M.H. (1987). Facilitating mother-infant communicative interaction in mothers of high-risk infants. Journal of Childhood Communication Disorders, 10(2):95-106.

Kritzinger, A.M. (1994). Vroeë Kommunikasieontwikkeling van Biologiese Risikobabas. Unpublished M Log Thesis, University of Pretoria.

Lahey, M. (1988.) Language Disorders and Language Development. New York: Macmillan Publishing Company.

Louw, B. (1986). Swart babas met gesplete .verhemelte: 'n Morfofunksionele studie. Unpublished D Phil Dissertation,
University of Pretoria.

Majnemer. A., Brownstein, A., Kadanoff, R. \& Shevell, M.I. (1992) A comparison of neurobehavioral performance of healthy term and low-risk preterm infants at term. Developmental Medicine and Child Neurology, 34:417-424.

Malan, B. (1993). Spraak-taalterapeutiese/oudiologiese dienslewering aan 0-24 maande hoërisikokinders in die SuidAfrikaanse konteks. Unpublished B Log Thesis, University of Pretoria

Mann, S.E. (1986). Impedansoudiometrie by neonate. Unpublished M Log Thesis, University of Pretoria.

Morris, S.E. \& Klein, M.D. (1987). Prefeeding Skills. Tuscan: Therapy Skill Builders.

Owens, R.E. (1984). Language Development. Columbus: Charles E. Merrill Publishing Company.

Pearce, P.S., Saunders, M.A., Creighton, D.E. \& Sauve, R.S (1988). Hearing and verbal-cognitive abilities in high-risk preterm infants prone to otitis media with effusion. Developmental and Behavioral Pediatrics, 9(6):346-351.

Piper, M.C., Kunos, I., Willis, D.M. \& Mazer, B. (1985). Effect of gestational age on neurological functioning of the very lowbirthweight infant at 40 weeks. Developmental Medicine and Child Neurology, 27:596-605.

Proctor, A. (1989). Stages of normal noncry development in infancy: A protocol for assessment. Topics in Language Disorders, 10(1):26-42.

Proctor, L.R. \& Kennedy, D.W. (1990). High-risk newborns who fail hearing screening: Implications for otological problems Seminars in Hearing, 11(2):167-176.

Rosenblith, J.F. (1992). In the Beginning: Development from Conception to Age Two. Newbury Park: Sage Publications.

Rossetti, L.M. (1990). Infant-Toddler Assessment. An Interdisciplinary Approach. Austin: Pro-ed.

Rossetti, L.M. (1993). Enhancing early intervention services to infants and toddlers and their families. Journal of Childhood Communication Disorders, 15(1): 1-6.

Salamy, A. \& Eldridge, L. (1991). Neonatal risk and hearing loss. Seminars in Hearing, 12(2):146-153.

Smith, A. (1992). Cuddling up like a joey in a pouch. Sunday Star, 20 September:3.

Sparks, S.N. (1989). Assessment and intervention with at-risk infants and toddlers: Guidelines for the speech-language pathologist. Topics in Language Disorders, 10(1):43-56.

Stjernqvist, K. \& Svenningsen, N.W. (1990). Neurobehavioral development at term of extremely low-birthweight infants. Developmental Medicine and Child Neurology, 32:679-688.

Touwen, B.C.L. (1990). Variability and stereotypy of spontaneous motility as a predictor of neurological development of preterm infants. Developmental Medicine and Child Neurology, 32:501508.

van Kleeck, A. \& Richardson, A. (1988). Language delay in the child. In Lass, N.J. et al. (eds.) Handbook of Speech-Language Pathology and Audiology. Toron to: B.C. Decker.

Walters, R.J. \& Shimizu, M.D. (1990). Acoustical immittance screening of infants. Seminars in Hearing, 11(2):177-85.

Zarnoch, J.M. \& Balkany, T.J. (1977). Tympanometric screening of normal and intensive care unit newborns: Validity and reliability. In Harford, E.R. et al. (eds.) Impedance Screening for Middle Ear Disease in Children. New York: Grune \& Stratton. 


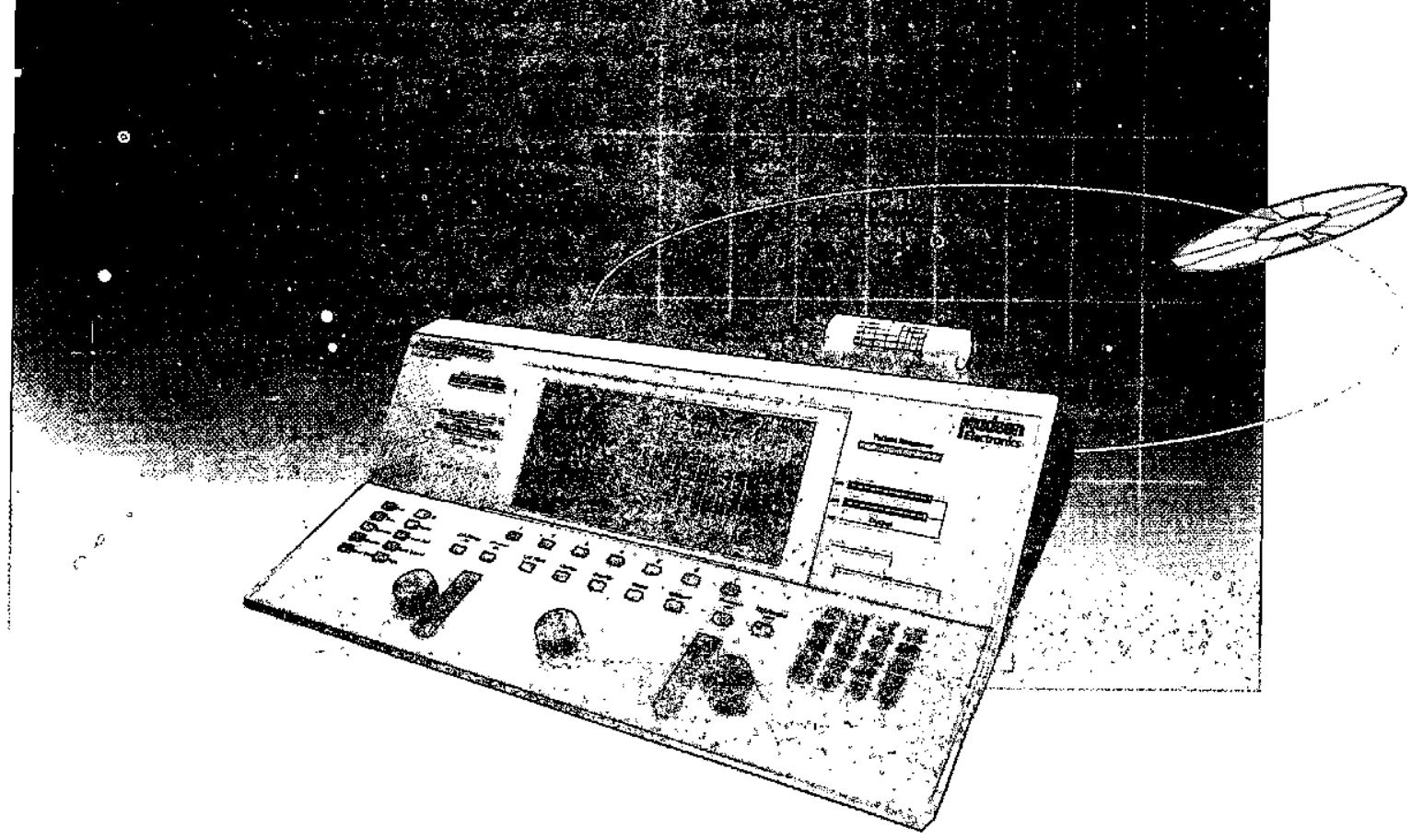

TWO SEPARATE AND IDENTICAL CHANINELS

SOFTMARE PACKAGE

THRESHOLDS PLOTTED ON SCREEN

2 YEAR GUARANTEE

FREQUENCIES :25 TO 20 O00 HZ

CUSTOAOZED PROTOCOLS

WORDLISTS STORED IN MEMORY

BUOLT IN PRINTER

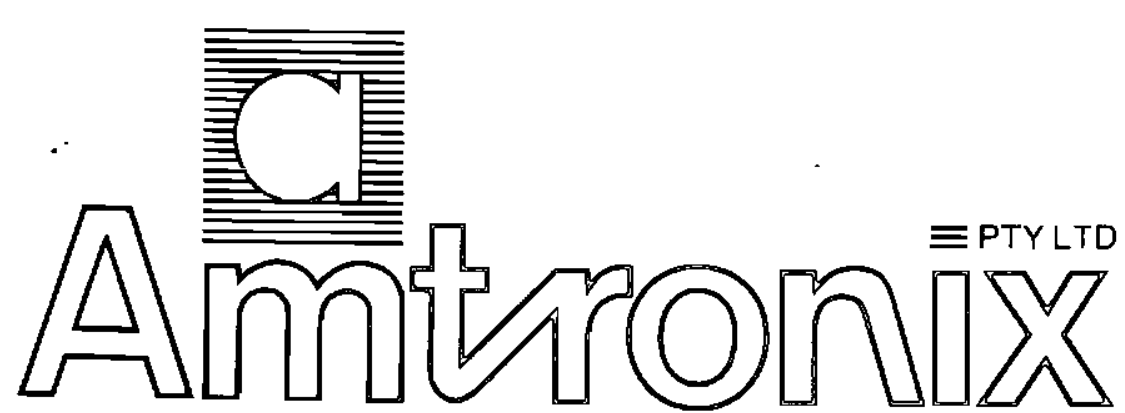

SOVEREIGN HOUS SOVEREIGN STREI BEDF.ORDVIEW 2008,

SOUTH AFRICA

P.O. BOX 630

BEDFORDVIEW

2008

SOUTH AFRICA

TEL: (011) 622-174

THE HEARING HEALTH CARE SPECIALISTS

FAX: (011) 622-130

Reg. №. 77/01577/07

The South African Journal of Communication Disorders, Vol. 42, 1995 Annivonir - breaking ine sound barrier 